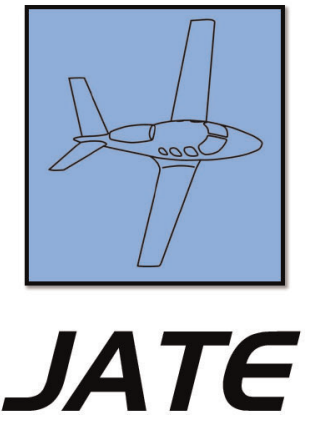

Journal of Aviation Technology and Engineering 9:2 (2020) 1-11

\title{
Modeling Land and Hold Short Operations: Balancing Safety and Arrival Rate
}

\author{
Kenneth A. Ward and Heather Owen-Perry
}

Embry-Riddle Aeronautical University

\begin{abstract}
Many airports conduct simultaneous operations on intersecting runways to increase the rate of takeoffs and landings. This requires landing aircraft to hold short of the intersecting runway, which incurs a safety risk of runway incursions in the process. A Monte Carlo simulation was conducted to analyze the traffic load at maximum operational capacity at Charlotte-Douglas International Airport in order to analyze the fleet types and the rate of those landing aircraft unable to stop short of the intersecting runway. The researchers used the actual and four alternative compositions of the subject airline's aircraft arrivals, interspersed among other airport traffic, to assess how such changes affect the rate of runway incursions, the rate of operations at the airport, and the mean number of passengers the subject airline can land per hour. The simulation revealed that runway length up to the hold short point was the biggest determinant of aircraft being unable to hold short. The total airport rate of operations decreased when heavy wake turbulence category aircraft were introduced. Despite heavy wake turbulence category aircraft carrying more passengers individually, the decreased operations rate also led to fewer passengers per hour that the subject airline could carry.
\end{abstract}

Keywords: land and hold short, LAHSO, runway incursion, airport, landings

\section{Introduction}

The coronavirus-2019 (COVID-19) pandemic caused a 48-61\% reduction in commercial air travel throughout the world (International Civil Aviation Organization [ICAO], 2020). However, the ICAO models of multiple recovery scenarios predicted a return to near-previous levels of air travel within a year (ICAO, 2020) and the industry will be postured to resume growth. While the COVID-19 pandemic is unique, comparison to other disease outbreaks and economic collapses, and subsequent airline industry recoveries, indicates the airline industry may be resilient to such short-term crashes in its economic models. Before the pandemic, the commercial airline industry anticipated a rapid increase in passenger travel over the next 20 years (International Aviation Transport Association [IATA], 2018). Though China likely will become the largest air passenger market, the United States expects to carry an additional 481 million new passengers (IATA, 2018). The forecasted increased passenger travel will place strains upon U.S. airport operations, and the industry will need to implement strategies for more efficient and safe operations. 
One option for managing airport capacity and operational efficiency is implementing a land and hold short operation (LAHSO) at an airport. In a LAHSO, an airport increases the rate of operations by using two intersecting runways simultaneously. Due to the increased risk of aircraft crossing active runways, additional safety restrictions are activated, including requiring aircraft to stop short of an intersecting runway or taxiway, or a point on the runway when landing (Palacios et al., 2010; Singh \& Meier, 2004). These designated points, called the "hold short point" by the Federal Aviation Administration (FAA), are identified on airport charts and implemented on long runways at some large airports (Palacios et al., 2010).

However, LAHSOs increase the possibility of runway incursions (Singh \& Meier, 2004), which are "any occurrence at an aerodrome involving the incorrect presence of an aircraft, vehicle, or person on the protected area of a surface designated for the landing and take-off of aircraft" (FAA, 2015b, para. 1). LAHSOs require that an aircraft be able to stop short of the LAHSO hold short point upon landing so that traffic on the intersecting runway has freedom of movement. Depending on touchdown location, runway conditions, or aircraft landing weight, an aircraft may be unable to hold short of the LAHSO hold short point.

One challenge to LAHSOs is the need to maintain spacing requirements (FAA, 2016). While airlines and air traffic controllers may wish to consider participating in LAHSOs at an airport as an opportunity to increase the traffic arrival rate (Ison et al., 2015), LAHSOs present a unique optimization challenge when attempting to maximize airport operations. First, LAHSOs increase the potential rate of operations by having more runways in operation simultaneously. Landing aircraft that exit the runway before crossing the intersecting runway also travel less distance on the ground and take less time to exit the runway, enabling subsequent traffic to land at a faster rate. Although air traffic controllers recommended LAHSOs as an option to increase arrival rate, subject to local conditions, controllers also recognized that minimum aircraft separation requirements and the types of aircraft servicing the airport may introduce delays (FAA, 2016; Ison et al., 2015). Furthermore, the operational rate will not only affect the number of aircraft that the airport can service each day, but the frequency and size of the airline's arriving aircraft also affect the airline's profits in the rate of arriving seat-miles per day. In essence, the problem becomes a delicate balance of priorities between the safety and business aspects of the airline.

This study simulates aircraft landings on intersecting runways at a real-world hub airport to model the likelihood of aircraft unable to hold short of the LAHSO hold short point (and thus are unable to participate in LAHSO), the maximum theoretical rate at which flight operations can be sustained, and rate of passengers per hour a subject airline can land at the airport given its fleet composition.
The purpose of this study was to conduct a simulation of 1,000 consecutive landing operations at an airport in each of 10 conditions to evaluate the rate of landing aircraft unable to land and hold short, the number of aircraft landings per hour, and the number of passenger arrivals per hour on the subject airline. This was done in order to understand how an airline's selection of fleet types to service the airport affects the rate of aircraft able to participate in LAHSOs, aircraft arrival rate at the airport as a whole, and the number of arriving passengers per hour.

The research questions of this study are as follows:

RQ1: How does an airline's selection of aircraft fleet types servicing an airport affect the percentage of aircraft able to participate in LAHSOs?

RQ2: How does an airline's selection of aircraft fleet types servicing an airport affect the airport's rate of aircraft landing per hour and the subject airline's rate of passenger arrivals per hour?

\section{Significance of the Study}

As airport operations continue to increase to support growing passenger traffic, it is imperative to identify the variables involved in aircraft operations. In particular, understanding the safety-related variables enables the airline and airport to quantify the risk while identifying opportunities to improve traffic flow. Therefore, this study simulates real-life situations at airports regarding LAHSOs and the operation's effects on runway incursion risks. Based on the results, airlines can develop appropriate airport-specific guidelines and policies, as they relate to LAHSOs and runway incursion risks, within the limitations of aircraft and safety. Further, while the model developed here is used to simulate landings at one particular airport, it can be adapted for any airport and runway with a LAHSO hold short point. Secondarily, identifying how fleet mix affects risk and traffic flow can educate airlines on risks related to operating flights into LAHSOimplemented airports.

\section{Assumptions}

The typical daily schedule and operations on multiple runways were not considered as this study considers the maximum rate of operations rather than simulating a day at the airport. Instead, the mean daily distribution from December 2018 was used to randomly assign aircraft in a simulated landing queue to a single runway at the maximum rate, based upon the percentage of daily operations made up of each fleet type and airline pairing. Without analyzing fullyear data, we made the assumption that operations in that month are representative of the typical monthly traffic at the airport selected. 
Once an aircraft was assigned to the simulated landing queue, this study assumes a perfect air traffic control agency manages the traffic flow to maximize the rate of arrivals. The model assumes an aircraft can land the instant the previous aircraft is off the runway and the minimum wake turbulence separation time has elapsed since the previous aircraft's landing. All aircraft capable of LAHSO were assumed to accept the LAHSO clearance and attempt the landing; no go-arounds were modeled.

Finally, the researchers made several assumptions regarding the distributions in the stochastic model. When inspecting the real-world aircraft landing speed data in the ADS-B database, all followed a normal distribution (Sun et al., 2019). Normal distributions were therefore assumed to impute the remainder of the aircraft landing speeds. The deceleration rate data were uniquely applicable to another airport and significantly underestimated the braking capabilities of the aircraft. The researchers, therefore, calculated the (higher) mean deceleration rate from airspeed and landing distance data, but calculated results from the observed normal distributions and standard deviations from existing data.

\section{Literature Review}

\section{Land and Hold Short Operation}

A LAHSO is an air traffic management procedure used to control airport capacity efficiency while balancing ground operational safety (FAA, 2016). The procedure, previously called simultaneous operations on intersecting runways (SOIR), involves having landing aircraft hold short of an intersecting runway or taxiway, approach/departure flight path, or another predetermined point on the runway to enable other aircraft to pass before continuing (FAA, 2016). While participation in LAHSO is entirely voluntary, a pilot denial of LAHSO clearance increases air traffic management complexity as the controller must revector other aircraft that are landing or taxiing at the intersecting runways or taxiways.

Local LAHSO development teams develop airportspecific procedures (FAA, 2016). When building LAHSO procedures, the teams must consider the airport's availability of at least 2,500 feet of available landing distance, measured from the landing threshold to the hold short point, and at least 2,000 feet of distance between the departure runway threshold to the intersection where the hold short clearance is given (FAA, 2016). Further, the team will identify the types of aircraft authorized to perform LAHSO, which includes developing a list of appropriate landing distances for all aircraft participating in LAHSO.

LAHSO provides new opportunities for air traffic controllers to coordinate more aircraft within the airspace, as it effectively makes an additional runway available. Air traffic controllers agreed with the utility of LAHSO: In a survey requesting air traffic controllers' thoughts on how management can reduce arrival delays, controllers stated that reduced separation between arriving aircraft and more use of LAHSOs, but the mix of arriving aircraft should be limited to reduce delays due to airspeed and wake turbulence separation (Ison et al., 2015).

However, with intersecting runways or taxiways comes potential for incursions. In fact, runway and taxiway geometry is a frequent contributing factor to runway incursion problems. In 2012 the FAA and several airports embarked in a 10- to 15-year airport design improvement program, yet existing complicated intersections still require additional attention and coordination from pilots and controllers (Vitagliao et al., 2018). Singh and Meier (2004) identified that cooperation of both pilots and air traffic controllers is necessary for minimizing runway incursion events.

The overall rate of runway incursions has increased nearly $80 \%$ since 2002 , while the rate of total airport operations has decreased during the same time period (FAA, 2015b; Mathew et al., 2017). In response, the FAA created the Runway Incursion Mitigation program in 2015. This program is aimed at identifying runway incursion causal factors and reducing the rate of occurrences (FAA, 2015b; Mathew et al., 2017).

According to Singh and Meier (2004), nearly $70 \%$ of reported incursion events are related to aircraft crossing runways. The most frequent incursion scenarios include: departing aircraft and a taxiing aircraft in a crossing scenario; an arriving and a departing aircraft in a tail-chase position; arriving aircraft and a departing aircraft in intersecting runway operations; or arriving aircraft and a taxiing aircraft in a crossing scenario (Singh \& Meier, 2004). As LAHSOs could include any one of these scenarios, there is a potential for incursions occurring at airports conducting LAHSOs. Counterintuitively, a study of ten years of data of runway incursions concluded that while LAHSOs seemingly present higher risk, "LAHSO incursions are very rare" (Biernbaum \& Hagemann, 2012, para. 5.1). As the data for successful LAHSOs without a corresponding incident were not recorded, there was no way to determine the denominator necessary to fully contextualize the number of LAHSO-related incursions (Biernbaum \& Hagemann, 2012).

\section{Selecting an Airport for Analysis}

A causal study conducted by Mathew et al. (2017) developed an econometric model for identifying the severity and likelihood of an incursion, as grouped by airport category, and the statistically significant variables which influence incursions. The study indicated that the severity of runway incursions has decreased, but the likelihood of a runway incursion has increased (Mathew et al., 2017). Of greater importance, the results indicated that runway incursions were more likely at large hub airports (Mathew et al., 2017). 
While any major U.S. airport would serve as a testbed to develop a simulation model, the researchers chose CharlotteDouglas International Airport (CLT). CLT was selected because it is the largest hub in the United States with intersecting runways, the third largest hub in the world, and serves as American Airlines' second largest hub, slightly behind American's primary hub at Dallas-Fort Worth International Airport and Delta Air Lines' Atlanta HartsfieldJackson International Airport hub (Reed, 2018). With 677 total daily departures from CLT, American Airlines carries 90\% of the airport's passengers (Reed, 2018). As such, CLT has high variety and volume in its arriving aircraft, with a major air carrier making up a significant portion of that volume, which creates an opportunity to study how one airline's fleet composition affects operations.

While CLT was selected for the purpose of developing a model to understand the effects of LAHSO and fleet types on airport operations rates, we note that CLT did not conduct LAHSOs at the time this paper was written. However, the main purpose of the study was to develop a model of LAHSOs and understand the interplay of LAHSO, fleet types, and arrival rate. The runway geometry at CLT and arriving aircraft provided the best mix of available data, and the model developed here can be applied to any airport, if given information about the runways and arriving aircraft. In particular, CLT's shorter Runway 5 has similar overall length and LAHSO hold short distance to those of other major airports, such as Boston's Runway 27 and Newark's Runway 11, while CLT's Runway 36R was comparable to the longer runways at other major airports configured for LAHSO.

\section{Use of Modeling to Study Runway Incursions}

Numerous researchers have modeled runway incursions (Mathew et al., 2017; Stroeve et al., 2016; Wilke et al., 2015), including some who have used Monte Carlo modeling (Stroeve et al., 2016); however, none have focused on LAHSO. Instead, much of the research has focused on either severity or causal factors.

Wilke et al. (2015) proposed a framework for modeling runway incursions. Though the research focused on incursion severity, it provides a useful support for also modeling potential incursions from LAHSOs. In the Wilke et al. (2015) analysis process, airport surface system architecture is first modeled. In later steps, data are concurrently collected from both safety data and airport characteristics. Both data collection processes included parallel identification of variables relevant towards safety assessments, and data sources on both runway incursion and airport characteristics data (Wilke et al., 2015). Further, the safety data would be mined for runway incursion severity and causal factors, with relevant variables extracted from the airport characteristics data, and concluding in data quality assessments (Wilke et al., 2015). Wilke et al. (2015) recommended completing the research with conducting statistical analysis on both data sources.

In another study on runway incursion occurrences, Matthew et al. (2017) used a multinomial logit model to simulate runway incursion for different airport sizes. Matthew et al. (2017) determined that the multinomial logit model was the most accurate because the dependent variable of runway incursion severity is ordered discrete choice data.

In their research of runway collision risks, Stroeve et al. (2016) used dynamic risk modeling and Monte Carlo simulation to review air traffic scenarios, which included aircraft landing and taxiing. The modeling processes enabled Stroeve et al. (2016) to account for the many entities involved in runway incursion scenarios, including aircraft performance, situational awareness, and environmental factors at the airport, and to determine collision probability from the simulations.

\section{Methodology}

As previous works demonstrated the utility of using simulation and Monte Carlo methods to model runway incursions (Stroeve et al., 2016; Wilke et al., 2015), the present research used a Monte Carlo analysis to simulate LAHSOs at the maximum possible arrival rate at CLT. The simulation used traffic data from December 2018, which included the fleet type and airline for all arriving aircraft. A Monte Carlo simulation was selected because many simulated landings can be conducted with no risk to the flying public, and the results can be used to make inferences about the population and rate of occurrences (Tureson \& Odland, 2018). Microsoft Excel was used for the simulation because it allowed airport and aircraft data to be stored and has robust randomization and cross-referencing functions. IBM SPSS was used to analyze the resultant data.

\section{Modeling the Airport and Daily Operations}

There are two intersecting runways of interest at CLT: Runway 5 and Runway 36R (Figure 1). In order to categorize the landings, the researchers calculated the distance from the runway thresholds along each runway centerline for the LAHSO hold short point, the last runway exit taxiway before the hold short point, and the location of the touchdown zone in which most landing rolls begin. This was accomplished by comparing the airport diagram (FAA, 2019) with satellite imagery in Google Maps, and using the Google Maps measurement tool to approximate distances from the runway threshold. The runway lengths were measured using the Google Maps measurement tool and were found to match the published runway length data, so this method was deemed valid to measure touchdown zone, taxiway, and hold short locations. The touchdown zone was defined by the distance from the runway threshold to the first touchdown zone identifier marking and the aiming 


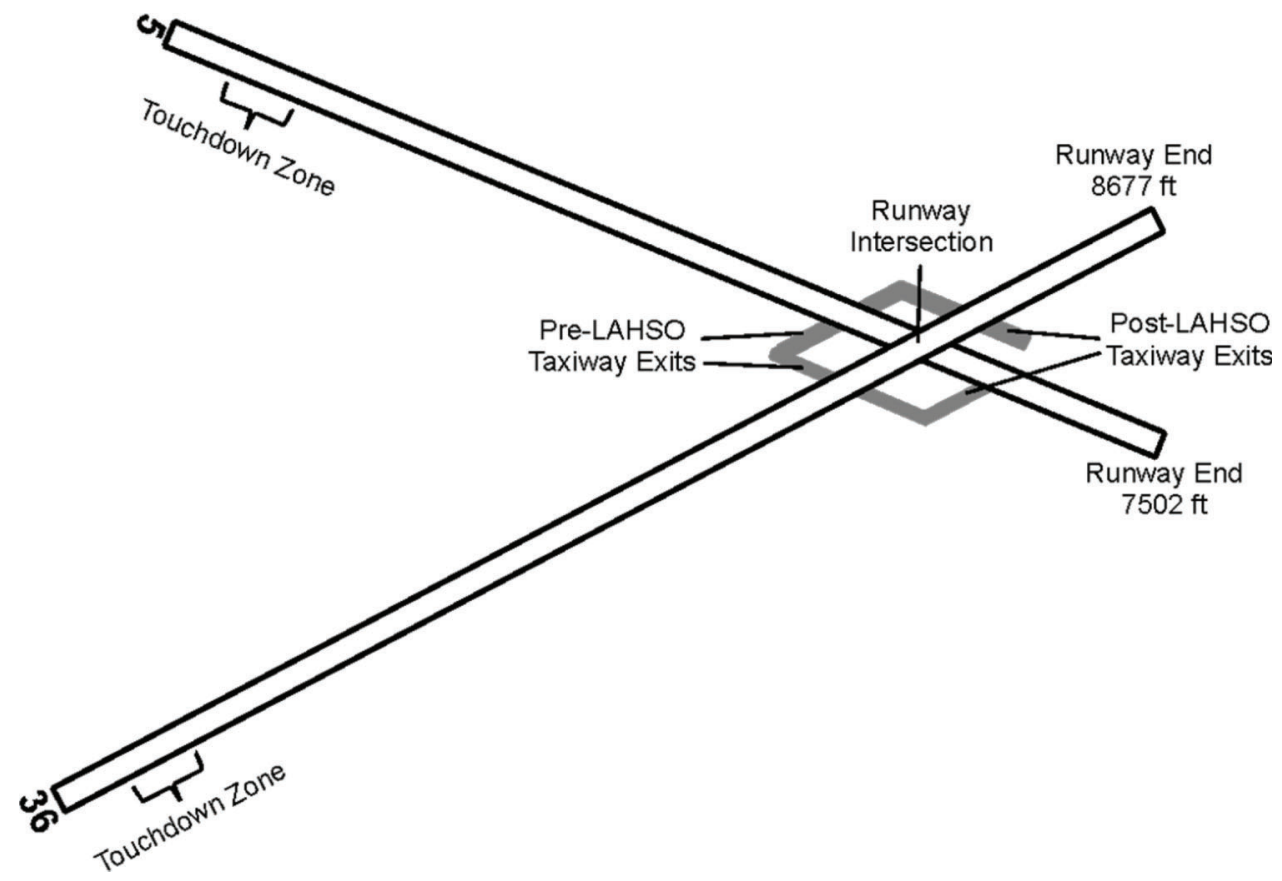

Figure 1. Locations of interest along intersecting runways at CLT.

point marking at 500 and 1,000 feet from the threshold, respectively, for both runways.

The number of aircraft arrivals at CLT by fleet type and airline for December 2018 was recorded in a publicly available database (Bureau of Transportation Statistics [BTS], 2019). There were 601 entries containing 30 unique airlines and 37 unique fleet types. The number of operations for the month divided by 31 provided the mean daily arrivals and number of passengers carried for each fleet type and airline pair. The data were reduced to the 23 fleet types that arrived at CLT at least 31 times during the month, thereby indicating daily operations. The fleet types were cross-referenced with aircraft type designations from the FAA (2018) to determine each wake turbulence category.

\section{Modeling Aircraft Performance}

A table of aircraft performance data was developed to model the landing speeds. The model was developed by using multiple sources, prioritizing those with more data fidelity. First, 10 of the 23 fleet types servicing CLT daily had data available in an open-source aircraft performance model, based upon data mining of real-world ADS-B (flight data broadcast) data (Sun et al., 2019). The data included landing speed and braking rate mean, minimums, maximums, and type of data distribution. All landing velocities had normal distributions, while braking rates followed normal and beta distributions.

The second priority source for aircraft landing speed was the Eurocontrol Aircraft Performance Database (Eurocontrol, 2019), where there were data for 11 additional fleet types. The database only provided a single value for each aircraft landing speed, which was assumed to be the mean. The remaining values of the standard deviation, minimum, and maximum were imputed. All landing speeds were assumed to be normally distributed, as all observed ADS-B landing speed distributions were normal (Sun et al., 2019). The known standard deviation of the Embraer 190 airspeed was 14.0 knots, while the known mean standard deviation of all larger aircraft was 8.1. For the Canadair and Embraer fleet types, 14.0 was used as the imputed standard deviation while 8.1 was used for Boeing and McDonnell Douglas aircraft. The minimum and maximum for all airspeeds in the ADS-B data equaled 1.44 standard deviations from the mean; 1.44 standard deviations from the mean was therefore set as the minimum and maximum airspeed in the imputed data. This represented an $85 \%$ confidence interval.

Deceleration data from ADS-B did not result in a useful model because the ADS-B data were dependent on the location of the airport under observation and the fact that pilots apply brakes depending on planned runway exits while managing passenger comfort (Kim et al., 1996). The deceleration rate was instead calculated from the landing speed and landing distance published in the Eurocontrol database based on the kinematic relationship between velocity and distance (Equation 1).

$$
a=v_{\mathrm{L}}^{2} /(2 s)
$$

On cursory inspection, the calculated values approximated the maximum braking values from the ADS-B data. This indicates the calculation provides a valid braking rate, which may also be more appropriate for this study simulating aircraft attempting to minimize their landing roll distance. The calculated braking rates were used as the 
mean braking rate for all aircraft. Given no information about braking rate distribution in the Eurocontrol database, standard deviations, minimums, and maximums from the ADS-B data were used where available and used to impute values for the remaining 13 aircraft. The mean standard deviation of 0.86 knots per second (the value from the recorded ADS-B data) and minimum and maximum fences of 1.64 standard deviations (also from recorded ADS-B data) from the mean, or a $90 \%$ confidence interval, were used to impute the remaining acceleration data.

For the remaining two aircraft, the Embraer 140 and Embraer ERJ-175, no data were available in either database. Data from the similar Embraer 145 and ERJ-170, respectively, were used to populate the two missing fleet types.

Taxi speeds were highly variable and dependent on the distance required to taxi (Ravizza et al., 2013). Additionally, taxi speeds for arriving aircraft are greater than those for departing aircraft, as they need to clear the active runway (Ravizza et al., 2013). Furthermore, reliable data regarding taxi speed and speed distribution by type of aircraft could not be found. Instead, the same minimum and maximum values were used for all aircraft. With no information about data distribution, taxi speed was defined by a uniform distribution between the minimum and maximum values of 30 and 50 knots, which were found to be the range of speeds for aircraft using high-speed exits from runways (Cassell \& Evers, 1998).

\section{Algorithm}

Microsoft Excel was used to build the simulation model of operations at CLT, starting with defining the controllable inputs in a series of lookup tables. First, the LAHSO hold short point and runway exit locations (in feet from threshold) were entered into the lookup table. Next, the published daily traffic statistics from the airport provided the number of fleet types and airlines servicing the airport, which were entered into the traffic lookup table to ensure randomly generated traffic was seeded with real-world arrival rates. Finally, aircraft performance data were used to build a reference table from which to simulate the landing behaviors of each simulated aircraft arrival.

Each of the 1,000 iterations of the algorithm (see Figure 2) began with randomly selecting a fleet type and airline pairing from the aircraft lookup table; as the table contained a cumulative percentage of arrivals for each fleet type and airline pairing, the random distribution approximated that of actual arrivals at CLT from December 2018 (BTS, 2019). Once the pairing was selected, the aircraft lookup table was referenced to determine the number of passengers and wake turbulence category for that aircraft. The previous arrival aircraft was referenced to determine its wake turbulence category, and the two aircraft categories were compared to FAA separation requirements to determine the minimum separation distance in miles. The wake turbulence separation was converted to seconds by dividing that distance by the landing speed.

The touchdown location was randomly generated from a uniform distribution within the touchdown zone, which was 500 to 1,000 feet from the threshold. The touchdown clock time was set to the later of when the previous aircraft departs the runway or when the separation time has elapsed from the previous aircraft's touchdown time. The time to decelerate to the taxi speed was calculated from landing speed, taxi speed, and deceleration rate (Equation 2). The location of the end of the landing roll was computed from the location of the aircraft touchdown, deceleration rate, and time to decelerate (Equation 3).

$$
\begin{gathered}
t_{\mathrm{a}}=\frac{v_{\mathrm{L}}-v_{\mathrm{T}}}{a} \\
s_{\mathrm{L}}=s_{0}+\frac{a t_{\mathrm{a}}}{2}
\end{gathered}
$$

The simulation then calculated the time required to taxi to the runway exit. For this simulation, only the first taxiways on either side of the hold short point were modeled. If an aircraft landing roll extends beyond the taxiway following the LAHSO point, the aircraft is assigned to exit at the far end of the runway. The clock time that the aircraft exits the runway was determined by adding the deceleration and taxi elapsed time to the landing clock time.

The next aircraft to land was then simulated to arrive either at the clock time immediately when the previous aircraft exited the runway or when the minimum wake turbulence time separation had elapsed since the previous aircraft's landing, whichever was greater. Aircraft wake turbulence separation categories were looked up from the aircraft table and compared to the prior aircraft that landed. Wake separation categories are listed in nautical miles, so the distance was converted to seconds based upon the following aircraft's landing speed. The aircraft arrival time was set to the number of seconds of separation following the previous aircraft's landing time.

At the conclusion of 1,000 landings, the total time to conduct operations was recorded, as was the total number of passengers carried by the subject airline. These were used to determine the number of passengers per hour carried by the subject airline.

Each simulated landing fell into one of two categories: either the aircraft ended its landing roll short of the LAHSO hold short point or the landing roll passed the hold short point. Aircraft not authorized to participate in LAHSOs were still modeled as landing on the subject runways to account for daily traffic, but they were excluded from counts of the aircraft unable to hold short of the LAHSO point. The available runway length and runway altitude at CLT preclude the DC-10, A330, 737-800, and CRJ-900 from participating in LAHSO (FAA, 2014). 


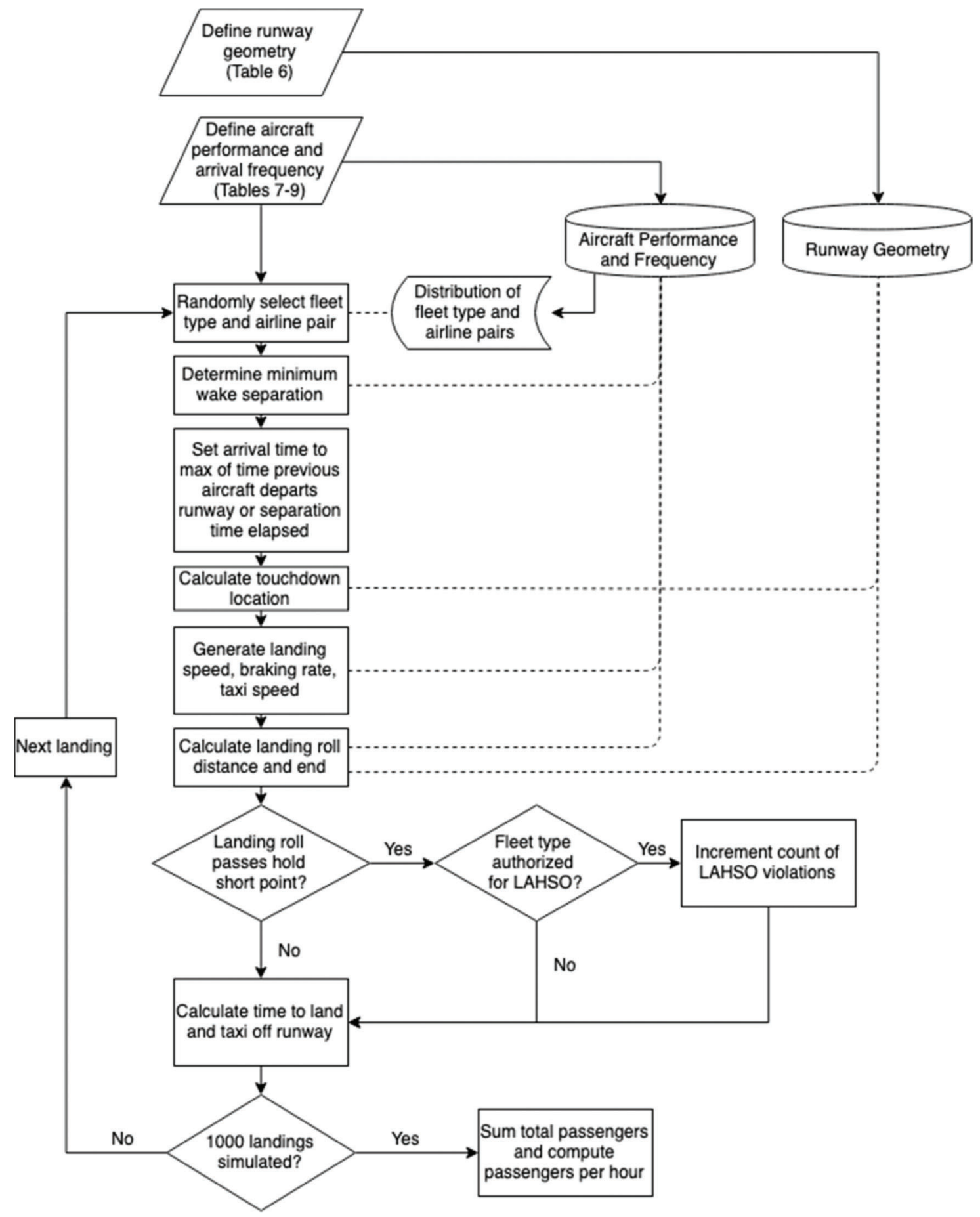

Figure 2. Simulation algorithm.

Model Execution and Data Analysis

The daily arrivals of American Airlines from archival data (BTS, 2019) were first examined to establish the baseline condition in which no changes are made from realworld arrival rates. American Airlines had 266.4 mean daily flights, using seven fleet types, which brought in a mean of 33,274 passengers per day (see Table 1).
American Airlines' A319, A320, A321, and 737-800 fleet types are similar categories of aircraft that carried between 101 and 141 mean passengers per flight, yet each aircraft has different performance characteristics. The 757-200 fleet type carries slightly more passengers with a mean of 153 passengers per flight but is a larger aircraft in the heavy wake turbulence category. The aircraft with the most daily arrivals was the A321, which was held constant during this analysis. 
Four hypothetical fleet compositions were developed to test the effect on operations if the subject airlines adjusted the mix of aircraft to emphasize the A319, A320, 737-800, and 757-200 fleet types instead. These compositions were developed by first setting the fleet type to be emphasized to 156.5 (the sum of A319, A320, 737-800, and 757-200 flights) and zeroing out the other two (see Table 1). In this manner, the number of daily flights could continue without disrupting established routes, although the total number of passengers serviced varied from 31,707 (A319 emphasized) to 35,814 (737-800 emphasized).

The researchers acknowledge this fleet mix adjustment may not be feasible given American Airlines' actual fleet and route structure, but the intent here was to determine the effect on operations from different fleet types. Only the subject airline's arrivals were adjusted, to simulate the effect on operations amidst normal daily traffic from other air carriers.

The model was then executed using existing airport traffic data and the four alternative fleet mixes, created by adjusting the numbers and fleet types of the subject airline's services. One thousand simulated landings were conducted on each runway for each of the five fleet composition conditions. Three dependent variables were analyzed using IBM SPSS statistical software: the rate of aircraft unable to hold short and therefore unable to participate in LAHSO, the time between aircraft touchdowns, and the rate of subject airline passengers per hour. As this study was designed to provide information to airline decision-makers and does not draw conclusions regarding the optimal balance of safety and operations, the results from each dependent variable were compared in separate analyses.

\section{Results}

The rate of aircraft crossing the LAHSO hold short point for all traffic and the subject airline were compared in each condition (see Table 2). The DC-10, A330, 737-800, and CRJ-900 were prohibited from participating in LAHSOs given the available runway length and altitude at CLT; their counts were excluded. There were 3,602 simulated landings by LAHSO-eligible aircraft on Runway 5, 1,661 from the subject airline.

Of those landings, 98 resulted in an aircraft passing the LAHSO hold short point during the landing roll (see Table 3), indicating eligible aircraft that were unable to participate in LAHSO for those landings. A chi-square test of homogeneity found that the rates of traffic unable to hold short in the different fleet mix scenarios were not significantly different when considering all airport traffic $(p=0.799)$. The proportions were also not significantly different when considering only the subject airline traffic $(p=0.305)$.

On runway 36R, there were 3,601 landings of aircraft participating in LAHSO, 1,674 from the subject airline. There were 19 LAHSO-participating aircraft unable to hold

Table 1

Experimental fleet composition conditions (subject airline only).

\begin{tabular}{|c|c|c|c|c|c|}
\hline Fleet type & Baseline & A319 emphasized & A320 emphasized & 737-800 emphasized & 757-200 emphasized \\
\hline Airbus A319 & 85.0 & 156.5 & - & - & - \\
\hline Airbus A320-100/200 & 39.1 & - & 156.5 & - & - \\
\hline Airbus A321 & 104.0 & 104.0 & 104.0 & 104.0 & 104.0 \\
\hline Airbus A330-200 & 3.7 & 3.7 & 3.7 & 3.7 & 3.7 \\
\hline Airbus A330-300 & 2.3 & 2.3 & 2.3 & 2.3 & 2.3 \\
\hline Boeing 737-800 & 30.3 & - & - & 156.5 & - \\
\hline Boeing 757-200 & 2.1 & - & - & - & 156.5 \\
\hline Grand total & 266.4 & 266.5 & 266.5 & 266.5 & 266.5 \\
\hline
\end{tabular}

Table 2

Rates of aircraft unable to hold short by subject airline and fleet mix strategy.

\begin{tabular}{|c|c|c|c|c|c|c|}
\hline Runway & Traffic & Baseline & A319 emphasized & A320 emphasized & 737-800 emphasized & 757-200 emphasized \\
\hline Runway 5 & All traffic & $2.07 \%$ & $3.02 \%$ & $2.98 \%$ & $2.66 \%$ & $2.81 \%$ \\
\hline Runway 5 & Subject airline & $2.01 \%$ & $1.60 \%$ & $2.81 \%$ & $4.67 \%$ & $3.02 \%$ \\
\hline Runway 36R & All traffic & $0.41 \%$ & $0.65 \%$ & $0.51 \%$ & $0.56 \%$ & $0.51 \%$ \\
\hline Runway 36R & Subject airline & $0.56 \%$ & $0.56 \%$ & $0.52 \%$ & $0.00 \%$ & $0.50 \%$ \\
\hline
\end{tabular}

Table 3

Median time between touchdowns in seconds for all airport traffic.

\begin{tabular}{|c|c|c|c|c|c|}
\hline Runway & Baseline & A319 emphasized & A320 emphasized & 737-800 emphasized & 757-200 emphasized \\
\hline Runway 5 & 60.71 & 60.83 & 60.53 & 59.18 & 62.76 \\
\hline Runway 36R & 73.74 & 74.18 & 73.65 & 72.64 & 77.69 \\
\hline
\end{tabular}



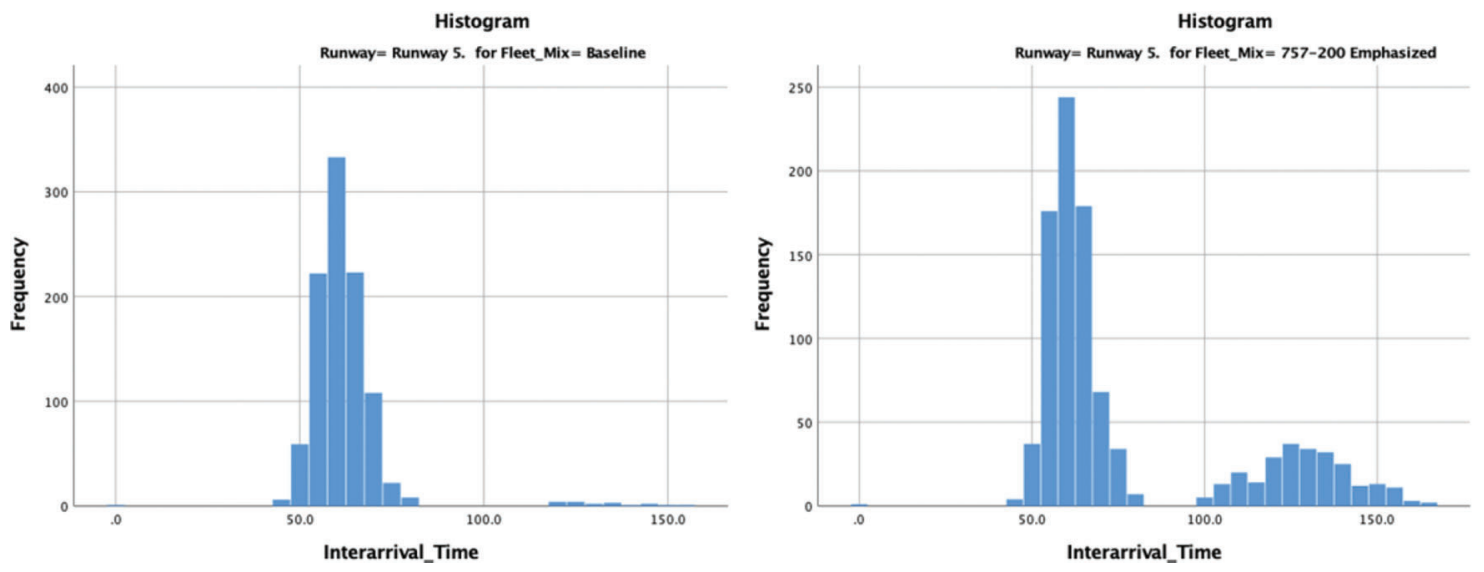

Figure 3. Histograms of times between touchdowns, baseline and 757-200 fleet mix.

short of the LAHSO hold short point on Runway 36R. The rate of traffic unable to hold short for the different fleet mixes was not significantly different when considering all airport traffic $(p=0.98)$ or just the subject airline traffic $(p=0.876)$.

Next, an analysis of whole-airport traffic arrival rates was conducted using the fleet mix as the independent variable and the time in seconds between landings as the dependent variable. The interarrival time followed bimodal distributions with clusters distributed under the two conditions of no delay and a delay of a large aircraft following a heavy aircraft (see Figure 3). The bimodal distributions violated assumptions for parametric analysis, so a nonparametric analysis was conducted.

A Kruskal-Wallis $\mathrm{H}$ test was performed to determine whether there were differences in touchdown-to-touchdown times between the fleet mix strategies for both runways. The assumptions of a continuous dependent variable, categorical independent variable, and data independence were met by the design of the simulation (Laerd Statistics, 2015). Distributions of the time between touchdowns were not similar for all groups, as exemplified by histograms for the baseline and 757-200 emphasized fleet mix. The distributions of interarrival times were significantly different between fleet mix conditions for both Runway $5\left(\chi^{2}(4)=191.088\right.$, $p<0.001)$ and Runway 36R $\left(\chi^{2}(4)=201.570, p<0.001\right)$.

The researchers used Dunn's (1964) procedure with a Bonferroni correction to make pairwise comparisons, which revealed statistically significant differences in interarrival times on Runway 5 between the baseline fleet mix (mean rank $=2,448.80$ ) and 737-800 fleet mix (mean rank $=$ 2,130.01) $(p<0.001)$ and between the baseline fleet mix and the 757-200 fleet mix (mean rank $=2,996.06$ ) $(p<0.001)$. Similarly, on Runway 36R there were significant differences between the baseline fleet mix (mean rank = $2,422.31$ ) and 737-800 fleet mix (mean rank $=2,168.89$ ) $(p<0.001)$ and between the baseline fleet mix and the 757-200 fleet mix (mean rank $=3,037.98)(p<0.001)$.

Finally, the sum of the interarrival times and the sum of passengers from each subject airline flight were used to compute the rate of passengers per hour in the simulated maximum operational rate (see Table 4). The rate of passengers per hour in the baseline, A319, A320, and 737800 emphasized fleet mixes predictably followed the passengers carried by the aircraft emphasized. While the 757-200 carried the most passengers of the fleet mixes emphasized, it had a low rate of passengers per hour, influenced by the longer wake turbulence separation times.

We also compared our simulated maximum operational rate to the published operational capacity for CLT to demonstrate that the model was comparable to, or had higher landing rates than, that observed in real operation. In the various simulated scenarios, between 50 and 60 simulated aircraft landed on runway 36R. The real-world high-demand operations rate at CLT with three northbound runways in operation is 161 landings per hour, approximately triple that of the single modeled runway (FAA, 2015a).

\section{Discussion, Conclusions, and Recommendations}

The most obvious conclusion one can make from the rate of aircraft passing the LAHSO hold short point during simulated landing rolls is that the rate of aircraft unable to participate in LAHSO depends on the available runway length. Runway 36R at CLT has 947 feet more than Runway 5 between the runway threshold and hold short point, which explains more overall LAHSO participation on Runway 36R.

The rate of aircraft unable participate in LAHSO on Runway 5 was still low but was affected by the fleet types of aircraft frequenting the airport. Increasing the proportion of A319 or 757-200 fleet types resulted in marginally significant decreases to the rate of eligible aircraft unable to participate in LAHSO. Upon inspecting the performance data of these aircraft, they had some of the slowest touchdown speeds; the A319 mean touchdown speed was 129 knots while the 757-200 mean touchdown speed was 130 knots. The deceleration rate for the A319 and 757-200 was nearly identical (mean of 3.2 and 3.1 knots per second, 
Table 4

Subject airline passengers per hour by fleet mix strategy.

\begin{tabular}{lccccc}
\hline Runway & Baseline & A319 emphasized & A320 emphasized & $\mathbf{7 3 7 - 8 0 0}$ emphasized & 757-200 emphasized \\
\hline Runway 5 & 2,997 & 2,570 & 2,931 & 3,422 & 2,654 \\
Runway 36R & 2,528 & 2,229 & 2,379 & 2,526 & 2,472 \\
\hline
\end{tabular}

respectively). These data point to initial speed being the main determinant of the end location of the landing roll.

Additionally, there are safety implications of runway length as a determining factor. First, as speed is the main determinant of the end location of the landing roll, high speed or unstable approaches could compound the risk of an aircraft being unable to stop at the hold short line. LAHSO clearances received late from air traffic controllers can distract pilots during a critical phase of flight. Further, crews are unable to review the taxi diagrams and plan the approach speeds accordingly if clearances are provided late. The late clearances also could compound incursion risk, if they are granted simultaneously with clearing another aircraft to cross further down the runway, and the landing aircraft was unable to manage speed during the approach to meet LAHSO clearance needs.

The next important finding was that while taxi time affected the rate of operations, it did not appear to be the cause of delays. Given that the researchers used the same taxi velocities for all aircraft, time to taxi was determined by the location of available taxiways. We only modeled the two closest taxiways to the hold short point and an exit at the runway end; real-world taxi times may be lower given the availability of more exits.

The time between arrivals only significantly increased when increasing the proportion of 757-200 fleet-type arrivals. All the other fleet types adjusted were of the large wake turbulence category, but the 757-200 was in the heavy category. Most of the remainder of traffic at CLT also fell into the large category; only 15.6 of 670.8 total mean daily arrivals were heavy aircraft. When the fleet mix emphasized the 757-200 fleet type, that proportion drastically changed, requiring nearly a quarter of the following aircraft to increase the time before the next landing, as federal regulations require a 5 nautical mile separation for large-category aircraft following a heavy-category aircraft. As a result, the maximum operational rate of the airport slowed with the change in wake categories of arriving aircraft.

By itself, the operational rate of the airport and the other traffic may not be the primary concern of an airline charged with transporting only its own paying customers. The case of the 757-200 emphasized fleet mix raised an interesting decision tradeoff. The 757-200 can carry more passengers at a time than the A319, A320, A321, and 737-800 (see Table 1) and may appear to be a useful option to increase passengers on a growing route segment. However, changing the arrival airport's balance of large and heavy wake category arrivals decreased the operational rate of the airport such that the subject airline transported fewer passengers per hour.

\section{Limitations}

This study was limited by the deceleration data from ADS-B data collected at another airport, which did not appear to match the conditions at CLT. Raw ADS-B data are available in open databases online, but the researchers lacked the software to interpret the data firsthand at the time that this study was conducted. Furthermore, airlineand airport-specific policies governing LAHSO acceptance, deceleration rates, and taxi speeds were not considered; this model therefore only considers capabilities and maximum theoretical airport operation rates, not real-world operations.

\section{Recommendations}

Future research can improve upon this study and methodology by including a step in which aircraft performance data are collected from the airport in question before developing the model. Using airport-specific performance data in the simulation may capture the nuances of pilot decisions governing performance uniquely applicable to the subject airport and runways, such as how taxi speeds and braking rates depend on taxiway locations (Ravizza et al., 2013). Such an additional step may lead to a simulation that models operations at any given airport more accurately.

The simulation revealed that speed at touchdown contributed to the length of the landing roll. Pilots can use this information to plan descent and landing profiles that minimize ground speed at touchdown, thereby decreasing the initial velocity and not relying on maximum braking power to exit the runway before the LAHSO hold short point. Controllers can use this information, coupled with the fact that runway length was a factor when conducting LAHSOs at the airport, to ensure adequate spacing for slowing aircraft. Landing aircraft should be assigned the longer of the intersecting runways, in terms of distance before the hold short point rather than total length.

While these hypothetical fleet mix scenarios only considered the airport's maximum operational rate rather than a pre-planned arrival sequence, it raises a few planning considerations. First, airline route planners should consider the entirety of traffic at airports when planning a fleet type to service a route when possible. Selecting a fleet type of a similar wake category to the remainder of traffic will 
reduce required wake separation distance and delays. In addition, if LAHSO is a possibility at the destination of a route segment, consideration should be given to finding an aircraft within the appropriate wake turbulence category that has the lowest touchdown speed of those that carry the necessary number of passengers.

\section{References}

Biernbaum, L., \& Hagemann, G. (2012). Runway incursion severity risk analysis. (Report DOT-VNTSC-FAA-12-13). Washington, DC: U.S. Department of Transportation.

Bureau of Transportation Statistics. (2019). Air Carriers: T-100 Domestic Segment (All Carriers) [Database]. Retrieved from https://www. transtats.bts.gov/DL_SelectFields.asp

Cassell, R., \& Evers, C. (1998, 31 October-7 November). Development of airport surface surveillance performance requirements. Paper presented at the Digital Avionics System Conference, Bellevue, WA. Retrieved June 20, 2019, from IEEE Xplore.

Dunn, O. J. (1964). Multiple comparisons using rank sums. Technometrics, $6,241-252$.

Eurocontrol. (2019). Aircraft Performance Database. Retrieved from https://contentzone.eurocontrol.int/aircraftperformance/default.aspx?

Federal Aviation Administration. (2014). Aircraft wake turbulence. (Advisory Circular 90-23G). Washington, DC: Federal Aviation Administration.

Federal Aviation Administration. (2015a). Airport capacity profiles: Charlotte/Douglas International. Retrieved from https://www.faa.gov/ airports/planning_capacity/profiles/

Federal Aviation Administration. (2015b). Runway incursions. Retrieved https://www.faa.gov/airports/runway_safety/news/runway_incursions/

Federal Aviation Administration. (2016). Land and hold short operations (LAHSO) (Order JO 7110.118A). Washington, DC: Federal Aviation Administration.

Federal Aviation Administration. (2018). Aircraft type designators (Order JO 7360.1D). Washington, DC: Federal Aviation Administration.

Federal Aviation Administration. (2019). Charlotte-Douglas International Airport [Airport Diagram]. Retrieved from https://aeronav.faa.gov/ d-tpp/1906/00078ad.pdf\#nameddest $=($ CLT $)$

International Aviation Transport Association [IATA]. (2018). IATA forecast predicts 8.2 billion air travelers in 2037 [Press release]. Retrieved from https://www.iata.org/pressroom/pr/Pages/2018-10-2402.aspx

International Civil Aviation Organization [ICAO]. (2020). Effects of novel coronavirus (COVID-19) on civil aviation: Economic impact analysis. Retrieved from https://www.icao.int/sustainability/Documents/
COVID-19/ICAO\%20COVID\%202020\%2007\%2006\%20Economic\% 20Impact.pdf

Ison, D., Weiland, L., McAndrew, I., \& Moran, K. (2015). Identification of air traffic management principles influential in the development of an airport arrival delay prediction model. Journal of Aviation/Aerospace Education \& Research, 24(2), 39. doi:10.15394/jaaer.2015.1618

Kim, B. J., Trani, A. A., Gu, X., \& Zhong, C. (1996) Computer simulation model for airplane landing-performance prediction. Transportation Research Record, 1562(1). doi:10.1177/0361198196156200107

Laerd Statistics. (2015). Kruskal-Wallis H test using SPSS statistics. Statistical Tutorials and Software Guides. Retrieved from https:// statistics.laerd.com

Mathew, J. K., Major, W. L., Hubbard, S. M., \& Bullock, D. M. (2017). Statistical modelling of runway incursion occurrences in the United States. Journal of Air Transport Management, 65, 54-62.

Palacios, R., Doshi, A., Gupta, A., Orlando, V., \& Midwood, B. R. (2010). Neural network models to detect airplane near-collision situations. Transportation Planning and Technology, 33(3), 237-255.

Ravizza, S., Atkin, J. A. D., Maathuis, M. H., \& Burke, E. K. (2013). A combined statistical approach and ground movement model for improving taxi time estimations at airports. Journal of the Operational Research Society, 64(9), 1347-1360. doi: 10.1057/jors.2012.123

Reed, T. (2018, January 31). American Airlines wants to grow in Charlotte; the airport is building as fast as it can. Forbes. Retrieved from https://www.forbes.com/sites/tedreed/2018/01/31/americanairlines-wants-to-grow-in-charlotte-the-airport-is-building-as-fast-as-itcan/\#2af35bb514a2

Singh, G., \& Meier, C. (2004). Preventing runway incursions and conflicts. Aerospace Science and Technology, 8(7), 653-670. doi: 10.1016/j.ast. 2004.08.001

Stroeve, S. H., Som, P., van Doorn, B. A., \& Bakker, G. J. (2016). Strengthening air traffic safety management by moving from outcomebased towards risk-based evaluation of runway incursions. Reliability Engineering and System Safety, 147, 93-108.

Sun, J., Ellerbroek, J., \& Hoekstra, J. M. (2019). WRAP: An open-source kinematic aircraft performance model. Transportation Research Part C, 98, 118-138. doi:10.1016/j.trc.2018.11.009

Tureson, K., \& Odland, A. (2018). Monte Carlo simulation studies. In B. B. Frey (Ed.), The SAGE encyclopedia of educational research, measurement, and evaluation (pp. 1086-1089). Thousand Oaks, CA: SAGE.

Vitagliano, L., Canter, G., \& Aland, R. (2018). Problematic taxiway geometry study overview. (Report DOT/FAA/TC-182). Washington, DC: U.S. Department of Transportation.

Wilke, S., Majumdar, A., \& Ochieng, W.Y. (2015). Modelling runway incursion severity. Accident Analysis and Prevention, 79, 88-99. 